Engineering Fracture Mechanics 77 (2010) 3143-3156

doi:10.1016/j.engfracmech.2010.08.010

\title{
An Inverse Method for Evaluating Weld Residual Stresses via Fatigue Crack Growth Test Data
}

\author{
Rui Bao ${ }^{1}$, Xiang Zhang ${ }^{2 *}$ \\ ${ }^{1}$ Institute of Solid Mechanics, School of Aeronautic Science and Engineering, \\ Beihang University (BUAA), Beijing, 100191, China \\ ${ }^{2}$ Department of Aerospace Engineering, School of Engineering, Cranfield University, \\ Bedford, MK43 0AL, U.K.
}

\begin{abstract}
This paper presents an inverse method for calculating the thermal residual stresses in welded specimens via measured fatigue crack growth rates. Firstly, fracture-mechanics superposition law has been used to extract the stress intensity factor due to residual stress contribution from measured crack growth rate. Secondly, a so-called $\mathbf{B}$ matrix has been established by performing finite element analysis. Residual stress distribution is then determined by solving linear algebraic equations relating the $\mathbf{B}$ matrix and residual stress intensity factors obtained from crack growth test data. The inverse method has been validated by a well-established residual stress distribution and corresponding stress intensity factor, and then applied to an $\mathrm{M}(\mathrm{T})$ sample in 2024-T3 alloy with a longitudinal weld. Agreement with the measured residual stresses is reasonably good and reasons for certain differences between the calculated and measured are discussed.
\end{abstract}

Keywords: weld joint; thermal residual stresses; crack growth rate; stress intensity factors; finite element method; inverse method.

\section{Nomenclature}

$a$

$B_{i j}$

$B^{-1}$

$B^{T}$

E

$K_{\text {app }}, K_{\text {res }}, K_{\text {tot }}$

$K_{a p p, \max }, K_{t o t, \max }$

$K_{\text {app, min }}, K_{\text {tot, min }}$

$\Delta K_{\text {app }}, \Delta K_{\text {tot }}$

$K_{\text {resi }}$

$K_{\text {crit }}$

$R$

$R_{\text {eff }}$

Hhalf crack length in middle-crack tension, $\mathrm{M}(\mathrm{T})$, specimen

B matrix component representing a stress intensity factor value for crack length $a_{i}$ under an applied unit stress at location $x_{j}$

inverse matrix of $\mathbf{B}$

transpose matrix of $\mathbf{B}$

Young's modulus

stress intensity factors (SIF) due to applied, residual and combined stress fields

SIF due to applied and combined stress fields at the maximum applied stress

SIF due to applied and combined stress fields at the minimum applied stress

SIF range due to applied and combined applied and residual stresses

SIF due to residual stresses at crack length $a_{i}$

apparent fracture toughness

nominal stress intensity factor ratio $\left(K_{\min } / K_{\max }=\sigma_{\min } / \sigma_{\max }\right)$

effective stress intensity factor ratio $\left(K_{t o t, \min } / K_{t o t, \max }\right)$

\footnotetext{
* Corresponding author. Tel.: +44 1234 754621; fax: +44 1234758203.

Email address: xiang.zhang@cranfield.ac.uk (X. Zhang)
} 


$\begin{array}{ll}\mathbf{S}_{\text {res }} & \text { residual stress matrix } \\ S_{\text {res } i} & \mathbf{S}_{\text {res }} \text { matrix elements corresponding to location } x_{i} \\ C, n, p, q & \text { material constants in the NASGRO fatigue crack growth rate law }\end{array}$

\section{Introduction}

It is well known that welding induced thermal residual stresses affect fatigue crack growth (FCG) rates, especially when crack growth path is perpendicular to the weld joint line. Apart from the early research in the 1970-1980s on traditional steel welds [1-2], this problem has recently been investigated in the friction stir welds (FSW) [3-5] and fusion welds [6-8]; both processes and the laser beam welding are now utilised in the joining of aluminium aircraft structures. Efforts have been devoted to the prediction of residual stress effect on FCG rates [3-10]. In these work residual stress effect is taken into account by incorporating the residual stress intensity factor, $K_{\text {res }}$, into empirical crack growth rate laws. For a given residual stress distribution, $K_{\text {res }}$ can be calculated by either the finite element method (FEM) $[8,11]$ or the weight function method (WFM) [1, 9-11]. Therefore, accurate determination of residual stresses is a key issue in the damage tolerance analysis of welded structures.

Current techniques for residual stress measurement include the diffraction methods and mechanical methods. The diffraction methods are well established and usually nondestructive. Synchrotron X-ray sources can be used to measure to a depth of a few centimetres, whereas neutron sources can measure much deeper (several tens of centimetres) and are suitable for very large engineering components [12-13]. However, both techniques are only available at large scale facilities and the tests are relatively time consuming. The laboratory based X-ray generators can only be used for surface measurement to a depth of a few microns. For some kinds of alloys, difficulties may arise in using the diffraction methods due to the relocation and/or preferred orientation of the grains in the heat affected zones (HAZ). The mechanical methods are mostly semi-destructive. The most popular mechanical methods are the hole-drilling and the cut-compliance method. The hole-drilling method is a well established and widely accepted technique, which involves introducing a small hole into the surface of a component, at the centre of a special strain gauge rosette, and measuring the relieved strains. It provides limited spatial resolution [14]. For the cut-compliance method, residual stress profiles are determined by successive extension of a slot and measurement of the resulting strains or displacements [15]. This method requires more test samples for separate tests of measuring residual stresses and FCG rates.

Donald and Lados [16] proposed an outstanding mechanical approach to determine $K_{\text {res }}$ in real-time during fatigue test, which is similar to the cut-compliance method and named as online crack-compliance method. The basic idea of this method is that the load-displacement relationships in the presence and absence of residual stresses are different. $K_{\text {res }}$ can be determined by measuring the change in displacement (or strain) at the maximum load for a given increment of crack extension and comparing this to the corresponding change in displacement (or strain) at zero load over the same increment of crack extension. Pasta and Reynolds [17] has applied this method together with a technique developed by Schindler [18] to evaluating the residual stresses in a FSW joint in Ti-6Al-4V. The on-line crack-compliance method is straightforward for understanding and easy for carrying out. However, the practical application of this method requires a high level of instrumentation precision, stability and linearity [16], which is more difficult for conducting test of large complex structural components. Furthermore, predominately elastic behaviour is assumed, the influence of the crack-tip plastic zone could contribute to erroneous calculations of $K_{\text {res }}$ [16]. 
Another, and more important, characteristic parameter in FCG tests is the crack growth rate $\mathrm{d} a / \mathrm{d} N$. In this paper, an approach is presented using the $\mathrm{d} a / \mathrm{d} N$ data to evaluate welding residual stresses. This can be regarded as an inverse method. The work was motivated by these facts: a) facilities for conducting FCG tests are available in most mechanical test laboratories; b) it is possible to extract $K_{\text {res }}$ from measured d $a / \mathrm{d} N$ test data; c) finite element method (FEM) is a powerful tool for correlating residual stress with $K_{\text {res }}$ for both simple test samples and complex structural configurations. The main advantage of this method is that the residual stresses are calculated from the same test sample that was fatigue tested, which is useful for establishing FCG rate and relating it to sample size and residual stress distribution. The test sample numbers are also reduced.

The present method is described in detail in the methodology section, which is followed by validation using a well-established residual stress distribution and the corresponding $K_{\text {res }}$. Analysis examples are from a variable-polarity plasma-arc (VPPA) welded M(T) sample in 2024 alloy tested under constant amplitude loads and constant $\Delta K$. Limitations are pointed out at the end the discussion section.

\section{Methodology}

\subsection{Concept}

Based on the principle of linear elastic fracture mechanics (LEFM), FCG rates can be correlated with the stress intensity factor $K$, which is the characteristic parameter of the crack tip stress field and is correlated by crack length and crack tip stresses. Therefore, the procedure of the proposed method to obtain residual stress distribution from the $\mathrm{d} a / \mathrm{d} N$ data contains two steps which are shown in Fig.1. The first step is to determine the $K_{\text {res }}$ from measured $\mathrm{d} a / \mathrm{d} N$; and then to evaluate the residual stresses from the derived $K_{\text {res }} \sim a$ relation. These two steps will be presented in details in sections 2.2 and 2.3.

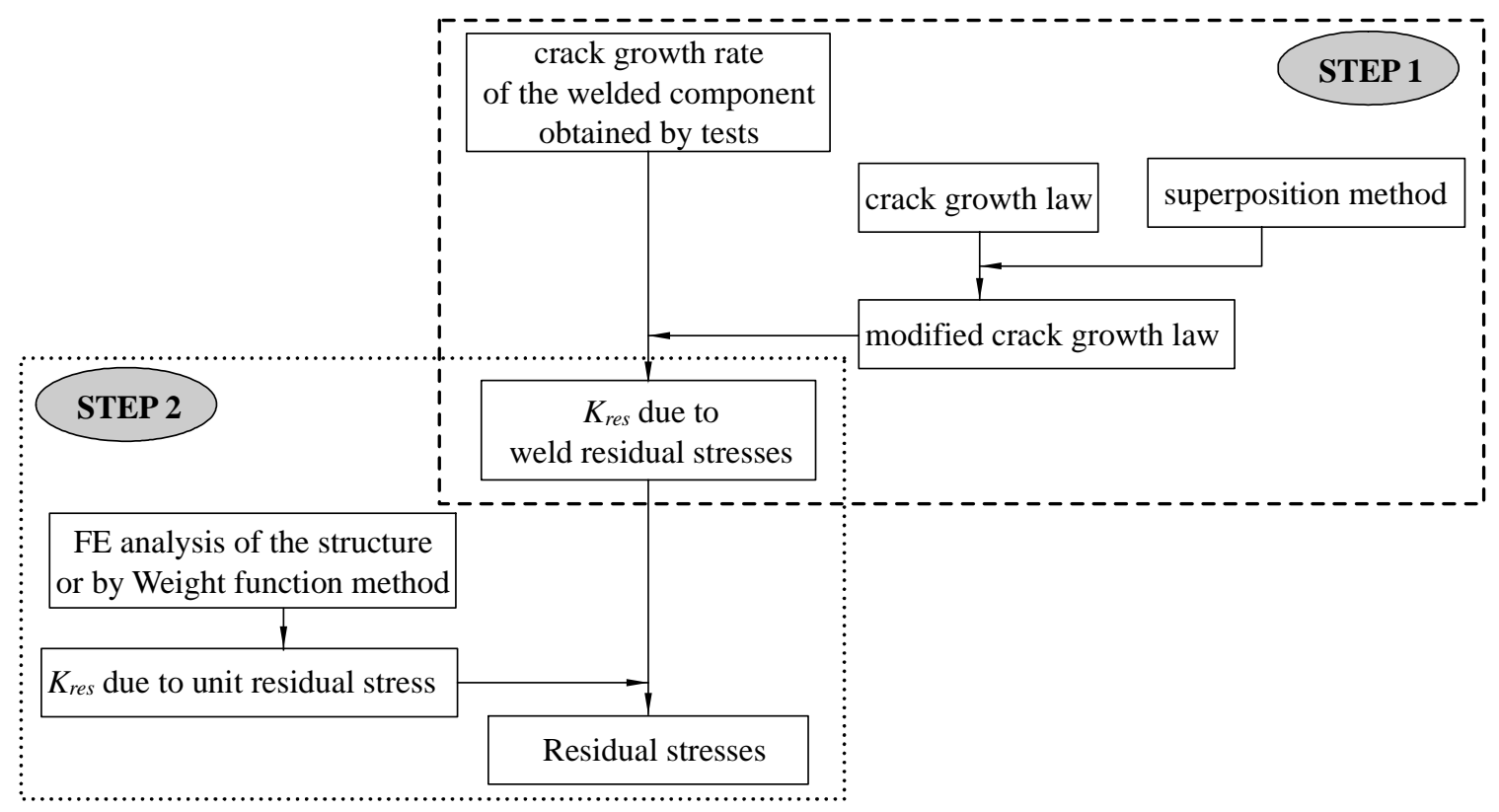

Fig.1 The concept and flowchart of the proposed inverse method.

The two step strategy, i.e. obtaining $K_{\text {res }}$ firstly and then residual stresses, is similar to the cutcompliance method and the on-line crack-compliance method. The main differences are summarised in Table 1. 
Table 1 Comparison of the solution steps in the cut-compliance, on-line crack-compliance and inverse methods

\begin{tabular}{ccc}
\hline Approach & $\begin{array}{c}\text { Step 1: } \\
\text { determination of } \\
K_{\text {res }} \text { from changes in }\end{array}$ & $\begin{array}{c}\text { Step 2: } \\
\text { evaluation of residual } \\
\text { stress by }\end{array}$ \\
\hline $\begin{array}{c}\text { Cut-compliance } \\
\text { compliance }\end{array}$ & $\begin{array}{c}\text { strain during cutting } \\
\text { displacement during crack } \\
\text { propagation }\end{array}$ & WFM \\
Inverse method & Fatigue crack growth rate & $\begin{array}{c}\text { WEM (or WFM if } \\
\text { available) }\end{array}$ \\
\hline
\end{tabular}

The advantages of determining $K_{\text {res }}$ from test $\mathrm{d} a / \mathrm{d} N$ data are: 1$)$ factors, e.g. crack closure, crack growth threshold, etc., can be taken into account by choosing an appropriate crack growth rate law; 2) residual stresses will come from the same specimen tested for the crack growth data; 3 ) there are no special requirements for the test system comparing with the online crack-compliance method. The reason for choosing the FEM in stead of the WFM in evaluating residual stresses from $K_{r e s}$ is that the modern welding techniques are widely used on manufacturing complex integral aircraft components for which weight functions are not readily available.

\subsection{Step 1: determination of $K_{\text {res }}$ from $\mathrm{d} a / \mathrm{d} N$ test data}

There are many empirical FCG laws to describe the relationship of $\mathrm{d} a / \mathrm{d} N$ and $\Delta K$ [19]. The generalized form of these laws can be expressed as:

$$
\frac{d a}{d N}=f(\Delta K, R)
$$

In the presence of residual stresses, the superposition rule is often employed to describe the stress field near crack tip due to the externally applied and residual stresses $[1,19]$. Then,

$$
\begin{gathered}
\Delta K_{t o t}=K_{t o t \max }-K_{t o t \min }=\left(K_{a p p \max }+K_{r e s}\right)-\left(K_{a p p \min }+K_{r e s}\right)=\Delta K_{a p p} \\
R_{e f f}=\frac{K_{a p p \min }+K_{r e s}}{K_{a p p \max }+K_{r e s}}
\end{gathered}
$$

The generalized form of the modified crack growth laws in the presence of residual stresses is:

$$
\frac{d a}{d N}=f\left(\Delta K_{a p p}, R_{e f f}\right)
$$

or

$$
\frac{d a}{d N}=g\left(K_{a p p \max }, K_{a p p \min }, K_{r e s}\right)
$$

$K_{a p p \max }$ and $K_{a p p \min }$ are fixed parameters controlled by the applied cyclic loads during FCG test, therefore, the relationship of $d a / d N$ and $K_{\text {res }}$ is unique and solvable.

In this study, the NASGRO equation [20], Eq. (6), is used. It takes account of the influences of the mean stress, the critical and threshold SIF, and plasticity-induced crack closure on FCG rates. It usually gives more accurate predictions provided that the material constants are available. 


$$
\begin{gathered}
\frac{\mathrm{d} a}{\mathrm{~d} N}=C\left[\left(\frac{1-f}{1-R}\right) \Delta K\right]^{n} \frac{\left(1-\frac{\Delta K_{t h}}{\Delta K}\right)^{p}}{\left(1-\frac{K_{\max }}{K_{c r i t}}\right)^{q}} \\
f=\frac{K_{o p}}{K_{\max }}= \begin{cases}\max \left(R, A_{0}+A_{1} R+A_{2} R^{2}+A_{3} R^{3}\right) & R \geq 0 \\
A_{0}+A_{1} R & -2 \leq R \leq 0 \\
a_{0}-2 A_{1} & R \leq-2\end{cases} \\
\Delta K_{t h}=\Delta K_{0} \frac{\left(\frac{a}{a+a 0}\right)^{\frac{1}{2}}}{\left(\frac{1-f}{\left(1-A_{0}\right)(1-R)}\right)^{1+C_{t h} R}}
\end{gathered}
$$

where, $C, n, p, q$ are empirical material constants derived from base material FCG test data. Coefficient $A_{0}, A_{1}, A_{2}$ and $A_{3}$ are parameters associated with the stress state (sample thickness). The thickness effect is also considered in $K_{\text {crit. }} a 0$ is the intrinsic crack length $(0.0015 \mathrm{in}$. or $0.0381 \mathrm{~mm}$ ).

According to the superposition rule, in the presence of residual stresses, $K_{\max }$ and $R$ are different from the originally applied values, consequently $f$ and $\Delta K_{t h}$ are affected. Modified NASGRO equation is given in eq. (9), in which $R_{\text {eff }}$ is given by Eq. (3); $f_{\text {eff }}$ can be obtained by substituting $R$ in Eq. (7) by $R_{\text {eff }}$; similarly $\Delta K_{\text {th eff }}$ is obtained by replacing $R$ and $f$ in Eq. (8) by $R_{\text {eff }}$ and $f_{\text {eff }}$, respectively.

$$
\frac{\mathrm{d} a}{\mathrm{~d} N}=C\left[\left(\frac{1-f_{\text {eff }}}{1-R_{\text {eff }}}\right) \Delta K_{a p p}\right]^{n} \frac{\left(1-\frac{\Delta K_{\text {theff }}}{\Delta K_{a p p}}\right)^{p}}{\left(1-\frac{K_{a p p \max }+K_{\text {res }}}{K_{\text {crit }}}\right)^{q}}
$$

In the experiments, $\mathrm{d} a / \mathrm{d} N$ vs. $a$ data are obtained by differentiating the crack length vs. load cycle relation that directly measured from FCG tests. Under constant amplitude loads, $K_{a p p}$ is a function of crack length $a$ and eq. (9) can be generalised as:

$$
\left(\frac{\mathrm{d} a}{\mathrm{~d} N}\right)_{i}=G\left(a_{i,} K_{\text {resi }}\right)
$$

Knowing $\mathrm{d} a / \mathrm{d} N$ vs. $a, K_{\text {res }}$ vs. $a$ relation can be calculated by solving the deterministic function expressed by eq. (9) or (10) using a numerical method. In this study, the NewtonRaphson iterative method [21] was employed. The solution process becomes much easier for the constant $\Delta K$ case.

\subsection{Step 2: evaluation of residual stresses from $K_{\text {res }}$ - $a$ relation}

For specimens with weld line parallel to the applied load (as shown in Fig. 2), the longitudinal residual stresses play a much more important role to the mode I crack growth rate compared to the transverse residual stresses. For the FSW process, the distribution of longitudinal residual stresses often has a characteristic double-peak in the HAZ, whereas for the fusion welds (e.g. VPPA and MIG) tensile residual stress part usually manifests multiple peaks as 
shown in Fig. 3. Once a residual stress distribution is given, corresponding $K_{\text {res }}$ vs. $a$ relation can be calculated via the FEM or WFM. The problem now is an inverse one, i.e. to find the distribution of residual stress from a given $K_{\text {res }} \sim a$ data that are obtained from experimental tests by the method described in Section 2.2.

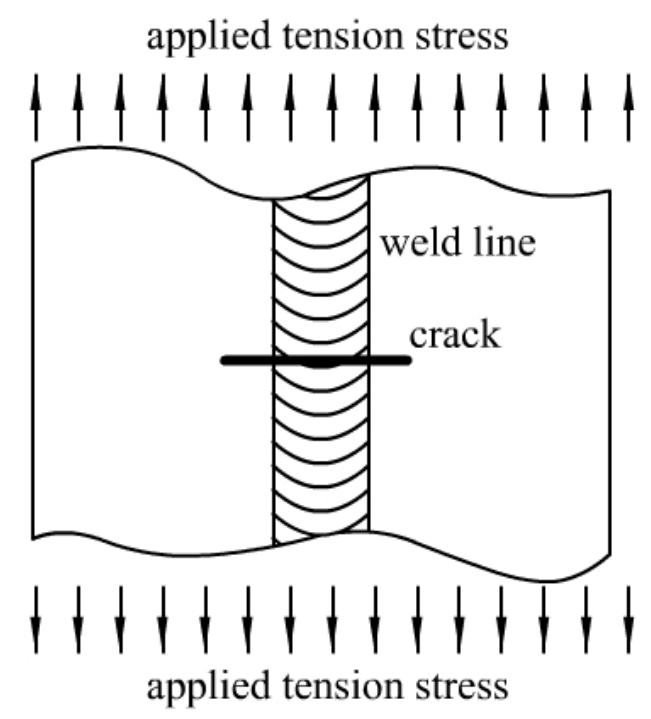

Fig. 2 Centre crack geometry with weld line parallel to the load direction.

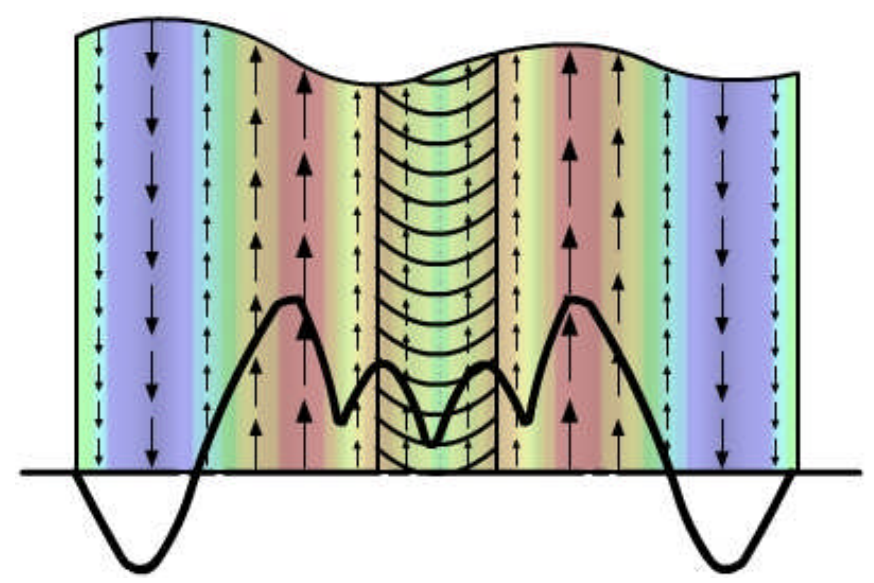

Fig. 3 Schematic of longitudinal residual stress field in a VPPA weld.

According to the theory of LEFM, the total SIF in the vicinity of a crack tip due to two or more different mode I loading systems can be found by an algebraic summation of the respective SIFs. Therefore a given residual stress field can be treated as a set of a series of discrete stresses $\left(\sigma_{1}, \sigma_{2}, \cdots, \sigma_{j}\right)$ acting at their respective locations $\left(x_{1}, x_{2}, \cdots, x_{j}\right)$ as shown in Fig. 4. Therefore, the sum SIF $K_{\text {res } i}$ at crack length $a_{i}$ due to these discrete stresses can be calculated by eq. (11):

$$
K_{\text {res } i}=\sum_{j=1}^{m}\left(K^{j}\right)_{i}
$$




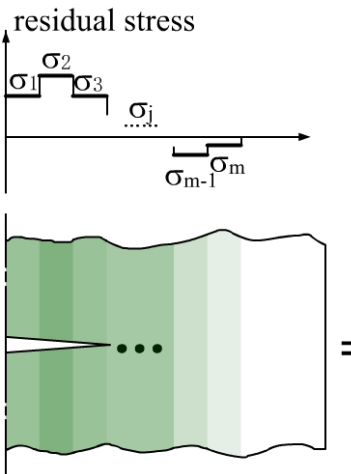

$K_{\text {res } i}$

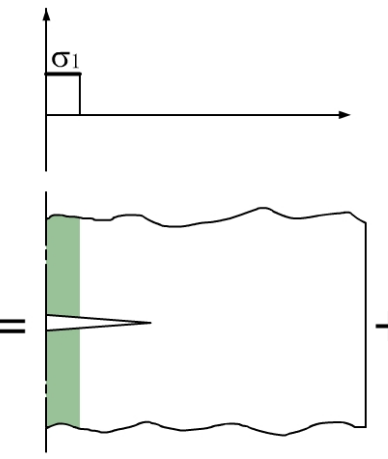

$\left(K^{1}\right)_{i}$

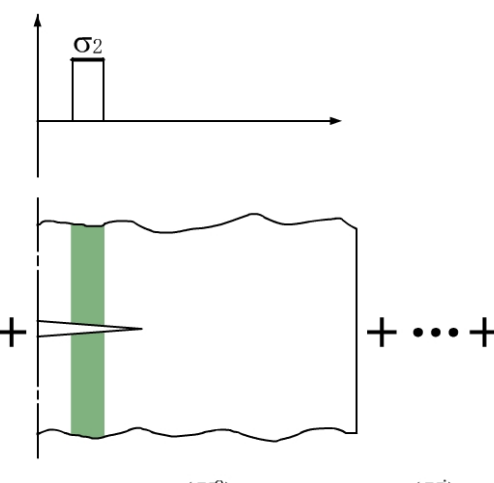

$\left(K^{\mathrm{j}}\right)_{i}$
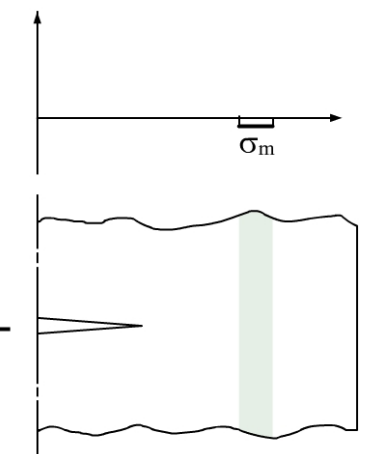

$\left(K^{\mathrm{m}}\right)_{i}$

Fig. 4 Summation of residual stress intensity factors due to discrete residual stresses.

If a unit residual stress is applied at location $x_{j}$, then the SIF value for crack length $a_{i}$ under this unit stress is defined as $B_{i j}$, which can be found by performing an FE analysis or WFM if the corresponding WF is available. $\left(K^{j}\right)_{i}$ in eq. (11) represents the actual SIF value when the residual stress at location $x_{j}$ is $S_{\text {res } j}$ rather than a unit value, hence:

$$
\left(K^{j}\right)_{i}=B_{i j} \cdot S_{\text {res } j}
$$

Furthermore, by adding the contributions of all discrete residual stresses for crack length $a_{i}$, $K_{\text {res } i}$ is found by:

$$
K_{\text {res } i}=\sum_{j=1}^{m}\left(K^{j}\right)_{i}=\left(B_{i 1}, B_{i 2}, \cdots, B_{i m}\right) \cdot\left(S_{r e s 1}, S_{r e s 2}, \cdots, S_{\text {resm }}\right)^{T}
$$

Let $\left(K_{r e s 1}, K_{r e s 2}, \cdots, K_{r e s n}\right)$ be the respective SIF value for each crack length $a_{i}(i=1,2, \cdots, n)$, Eq. (12) can be generalised to be:

$$
\left[\begin{array}{cccc}
B_{11} & B_{12} & \cdots & B_{1 m} \\
B_{21} & B_{22} & \cdots & B_{2 m} \\
\vdots & \vdots & \ddots & \vdots \\
B_{n 1} & B_{n 2} & \cdots & B_{n m}
\end{array}\right]\left\{\begin{array}{c}
S_{r e s 1} \\
S_{r e s 2} \\
\vdots \\
S_{r e s m}
\end{array}\right\}=\left\{\begin{array}{c}
K_{\text {res } 1} \\
K_{\text {res } 2} \\
\vdots \\
K_{r e s n}
\end{array}\right\}
$$

It can be imagined that a unit stress would have no contribution to the SIF value when it is applied in front of the crack tip, such as stress $\sigma_{m}$ in the example illustrated in Fig. 4. Therefore, $B_{i j}=0$, when $x_{j}>a_{i}$. Hence, if one choose $x_{i}=a_{i}$ for $B_{i i}, \mathbf{B}$ will be a lower triangular matrix. It is also understood that a unit stress that is applied behind but adjacent to the crack tip will have the maximum influence on the $\mathbf{B}$ matrix diagonal element $B_{i i}$, which is in contrast with those unit stresses located much farther behind the crack tip that produce the $B_{i j}$ elements.

When $m=n$, we have:

$$
\mathbf{S}_{r e s}=\mathbf{B}^{-1} \mathbf{K}_{r e s}
$$

It means that the distribution of residual stress can be found once the $\left(K_{\text {resi }}, a_{i}\right)$ data is available and the $\mathbf{B}$ matrix for discrete unit stresses is established. In this study, the linear algebraic equations are solved by the Gauss-Jordan elimination method [21]. 
If $m<n$, i.e. the unit stress locations $(m)$ is less than the number of incremental crack length $(n)$, the solution of $S_{\text {resi }}$ can be obtained by solving eq. (16):

$$
\mathbf{S}_{\text {res }}=\left(\mathbf{B}^{T} \mathbf{B}\right)^{-1} \mathbf{B}^{T} \mathbf{K}_{r e s}
$$

However, for the circumstance of $m>n, \mathbf{S}_{\text {res }}$ cannot be determined.

In the determination of $\mathbf{B}$ matrix using FEM or WFM, residual stresses are dispersed artificially in $m$ locations; hence one can choose to set $m=n$, which makes it easier to solve eq. (15).

Following examples and discussion are based on $m=n$, and the selection of the unit stress location $x_{i}$ for $B_{i i}$ to be the same as the location of crack length $a_{i}$.

The most important task in this analysis is to determine the $\mathbf{B}$ matrix. Elements in the $\mathbf{B}$ matrix are essentially SIF values corresponding to a specified location of unit stress and crack length. The WFM method is suitable for simple and idealised configurations if appropriate WFs are available. However, FEM is used in this work. Our intension is to develop a uniform FEM-based approach for general geometries, including introducing residual stress into FE models and calculating the $\mathbf{B}$ matrix elements. A comparison of the WFM and FEM in calculating the $\mathbf{B}$ matrix is presented in section 5 .

\section{FE analysis to obtain $B$ matrix}

\subsection{FE model}

Analyses were performed by a 2D FE model with higher order 8-node quadrilateral elements. The ANSYS code was employed. Crack tip singularity elements transformed from the conventional quadrilaterals by moving the mid-nodes to quarter point are used around the crack tip. SIFs are calculated using the displacement method embedded in the ANSYS code using the command "KCALC".

Since the elements in $\mathbf{S}_{r e s}$ obtained by eq. (15) have discrete values, $S_{r e s i}$ is the average of the residual stress between location $x_{i-1}$ and $x_{i}$. The increment of $x_{i-1}$ and $x_{i}$ depends on the finite element size, which is set to be $1 \times 1 \mathrm{~mm}$ in this study; therefore, residual stress value within every $1 \mathrm{~mm}$ distance could be obtained. Elements near the crack tip are refined, see Fig. 5.

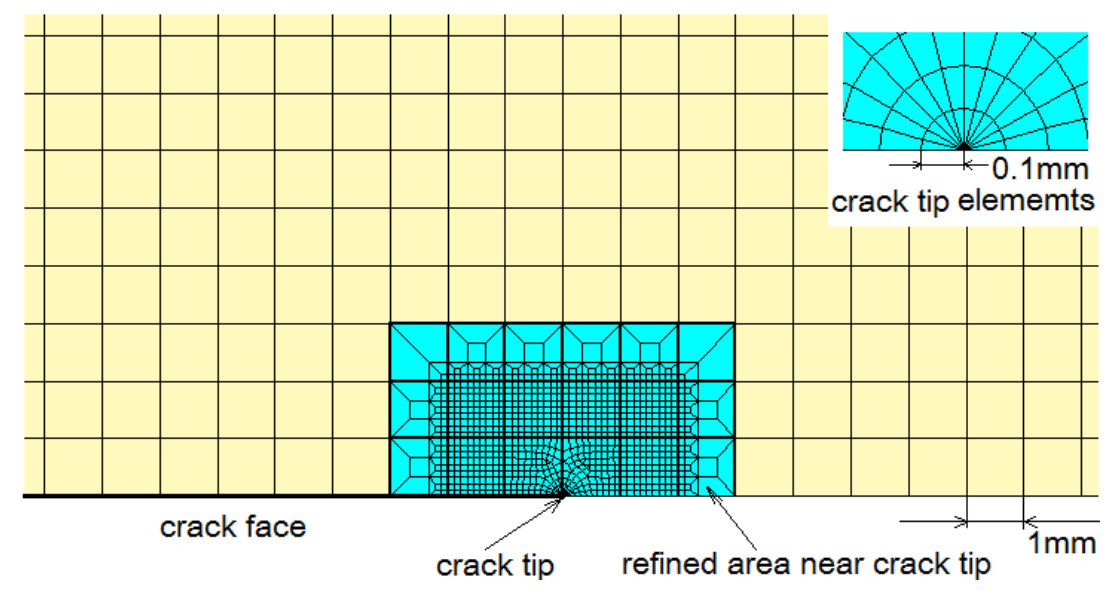

Fig. 5 FE model and crack-tip elements. 
Element size around the crack tip is $0.1 \mathrm{~mm}$ (insert of Fig. 5). However, in the crack tip region, residual stresses within the $1 \times 1 \mathrm{~mm}$ grid are assumed to have uniform values when solving eq. (15).

\subsection{Validation of FE model via calculating $K_{\text {res }}$ (forward method)}

Firstly, $K_{\text {res }} \sim a$ relation is calculated for a given residual stress field using the forward method. Several methods have been developed to input residual stresses into FE models, e.g. inputting equivalent displacements or inputting measured residual stresses. In this study, residual stresses are inputted directly into the FE model as an initial stress state using the ANSYS command "INISTATE". Since the longitudinal residual stresses are almost uniform along the $y$-axis according to the measured data [6,7], measured residual stress filed is modelled by applying a series of discrete values of $\left(\sigma_{1}, \sigma_{2}, \cdots, \sigma_{n}\right)$ acting at their respective $x$-axis locations $\left(x_{1}, x_{2}, \cdots, x_{n}\right)$ and keeping each individual stress value constant along the $y$ axis.

A benchmark test was conducted to validate the FE model. The purpose was to calculate the SIF for a mode-I crack located in a one-dimensional residual stress field as shown in Fig. 6. It is a center crack tension geometry with infinite width. Residual stress field described by eq. (17) and Fig. 6 was modelled as initial stresses in the FE model as previously described. Numerically computed SIFs for $c=10 \mathrm{~mm}$ and $\sigma_{0}=1 \mathrm{MPa}$ are compared with the analytically derived, eq. (18) [22]. Since the stress intensity factor solution in eq. (18) and [22] is for an infinite width condition, we choose the whole width $W=600 \mathrm{~mm}$ and maximum half crack length $40 \mathrm{~mm}$ in our FE model, which is close to the infinite width condition. The comparison is shown in Fig. 7 indicating an excellent agreement.

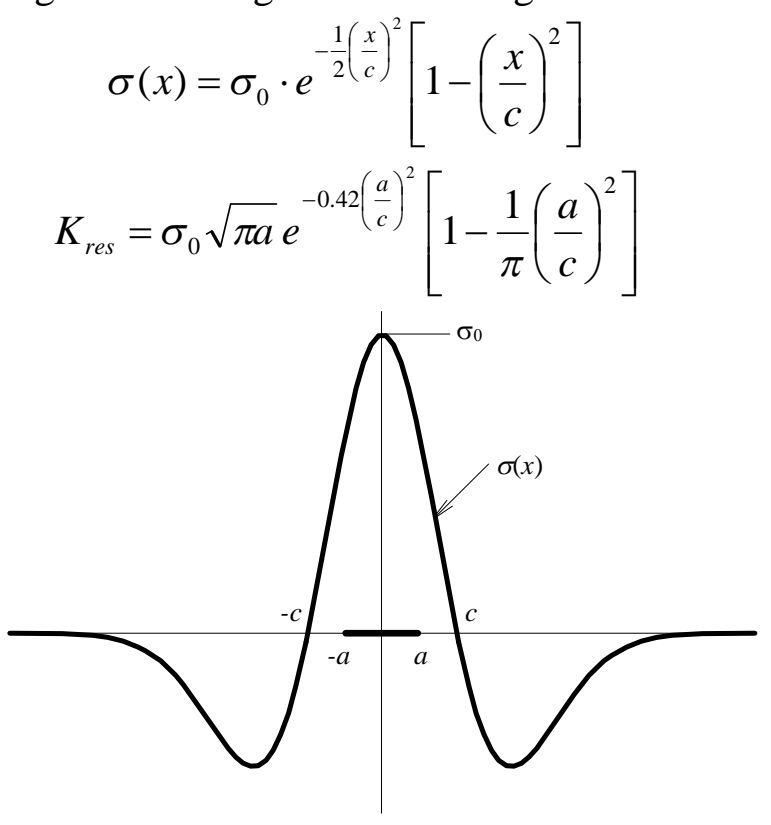

Fig. 6 One-dimensional residual stress field (longitudinal) [22]. 


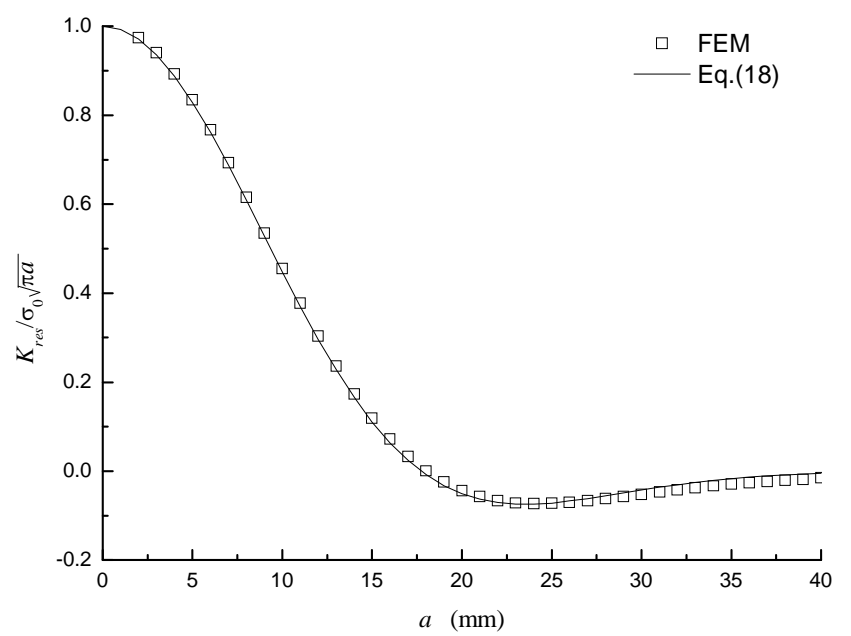

Fig. 7 Comparison of analytical and numerical $K_{\text {res }}$ for mode-I crack subjected to onedimensional longitudinal residual stress field.

\subsection{Calculation and validation of $B$ matrix (inverse method)}

Since element $B_{i j}$ in the $\mathbf{B}$ matrix is the SIF corresponding to unit stress applied over distance $\left(x_{j-1}, x_{j}\right)$ at crack length $a_{i}, B_{i j}$ can be determined by introducing unit tension stress to the elements located within $\left(x_{j-1}, x_{j}\right)$, and then calculating SIFs of different $a_{i}$ by the FEM. Here we set $x_{j}=j, a_{i}=i(i, j=1,2, \cdots, n)$.

It should be mentioned that $B_{i j}$ is the SIF derived from the unit tension stress only. However, if only a unit tension stress is introduced to the FE model, there will be compressive stresses in the adjacent elements to where the unit tension stress is applied to satisfy the self equilibrium requirement. A way to balance the unit tension stress is to apply a unit compression stress in front of and away from the crack tip. As previously mentioned (section 2.3), a compressive unit stress applied in front of the crack tip will not contribute to the calculated SIF value, however, it will change the redistributed stress field to ensure that the SIF is entirely caused by the unit tension stress. Fig. 8a and b illustrate the comparison of redistributed stresses in the FE model (with no crack) after the self equilibrium steep between the balanced and unbalanced unit stress. Fig. 8c shows the resultant nodal solution of $\sigma_{y}$ along the $x$-axis, which indicates clearly the existence of distributed compressive stresses in the case of introducing only the unit tension stress. The presence of these compressive stresses will affect the $B_{i j}$ value. For the two cases in Fig. 8a and b, the SIF value at two crack lengths are given in Table 2 to demonstrate the influence of unit compressive stress on $B_{i j}$.

Table 2 Comparison of the calculated SIF due to balanced and unbalanced initial unit stress (unit tension stress acts at 5-6 mm; unit compression stress is at $35-36 \mathrm{~mm}$ )

\begin{tabular}{c|c|c|c}
\hline \multicolumn{2}{c|}{ Crack length $a_{i}(\mathrm{~mm})$} & 6 & 10 \\
\hline $\begin{array}{c}\mathrm{SIF} \\
(\mathrm{MPa} \sqrt{\mathrm{m}})\end{array}$ & $\begin{array}{c}\text { unbalanced unit stress } \\
\text { (Fig. 8a) } \\
\text { balanced unit stress } \\
\text { (Fig. 8b) }\end{array}$ & 0.04996 & 0.01186 \\
\hline \multicolumn{2}{c|}{ Error of SIF (\%) } & -2.42 & -11.89 \\
\hline
\end{tabular}




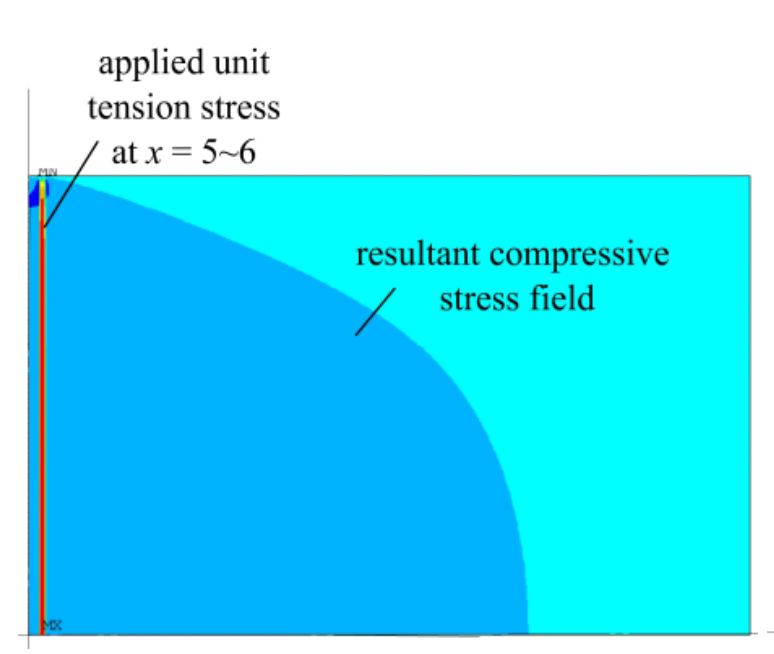

(a)

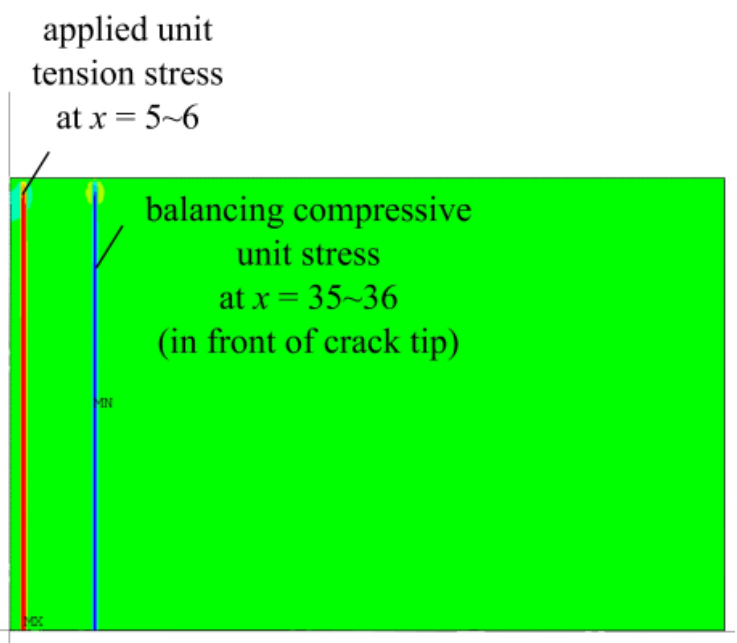

(b)

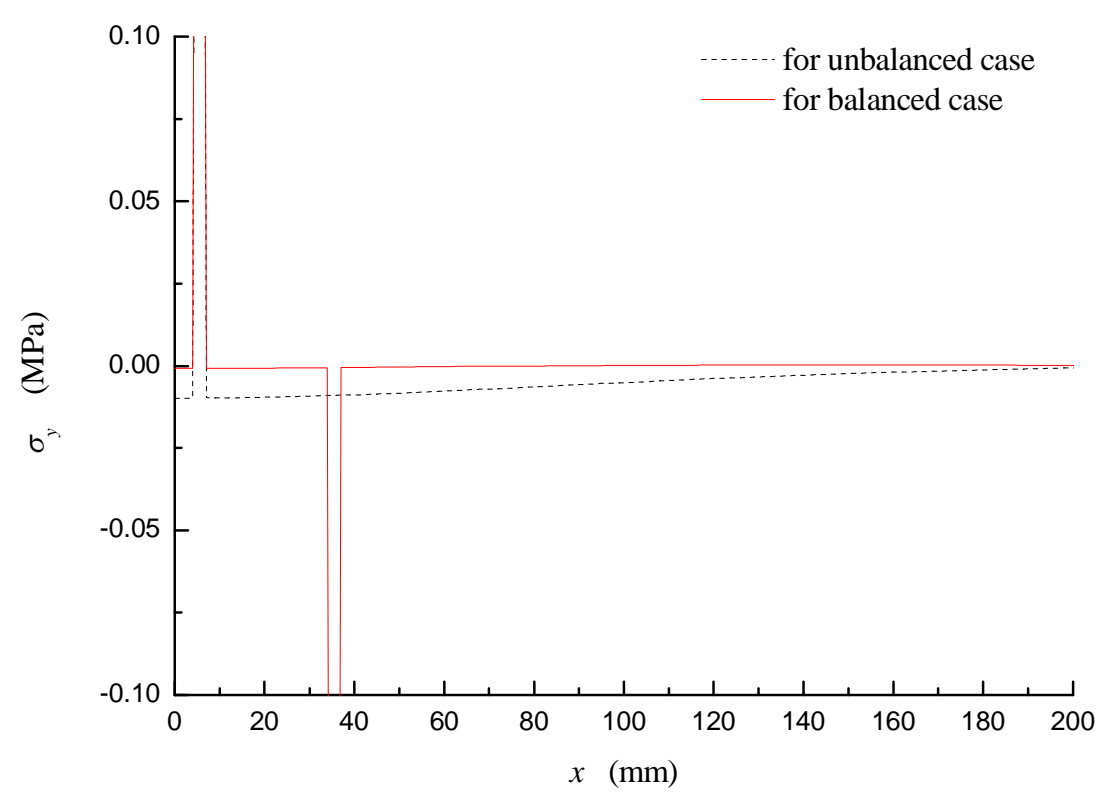

(c)

Fig. 8 Redistributed initial stress fields in the FE model $(W=600 \mathrm{~mm})$ after self equilibrium: (a) introducing only unit tension stress (unbalanced), (b) introducing self-balanced initial stresses, (c) comparison of the nodal stress $\sigma_{y}$ along $x$-axis of the FE model for the two cases

In order to validate the calculated $\mathbf{B}$ matrix, the benchmark example used in the forward analysis (from given $\sigma_{\text {res }}$ to find $K_{\text {res }}$ ) was used again for an inverse analysis. The geometry and residual stress field and $K_{r e s}$ are given in Fig. 6 and eqs. (17) and (18). Elements $B_{i j}$ for this geometry ( $W=600 \mathrm{~mm}$ ) corresponding to various crack length $a_{i}$ under unit stress acting on different locations $x_{j-1} \sim x_{j}$ are listed in Appendix 1. Calculated residual stress distribution is shown in Fig. 9 showing excellent agreement with the theoretical solution, Eq. (17) [22]. This exact agreement validates the inverse method and the $\mathbf{B}$ matrix for the $\mathrm{M}(\mathrm{T})$ geometry. 


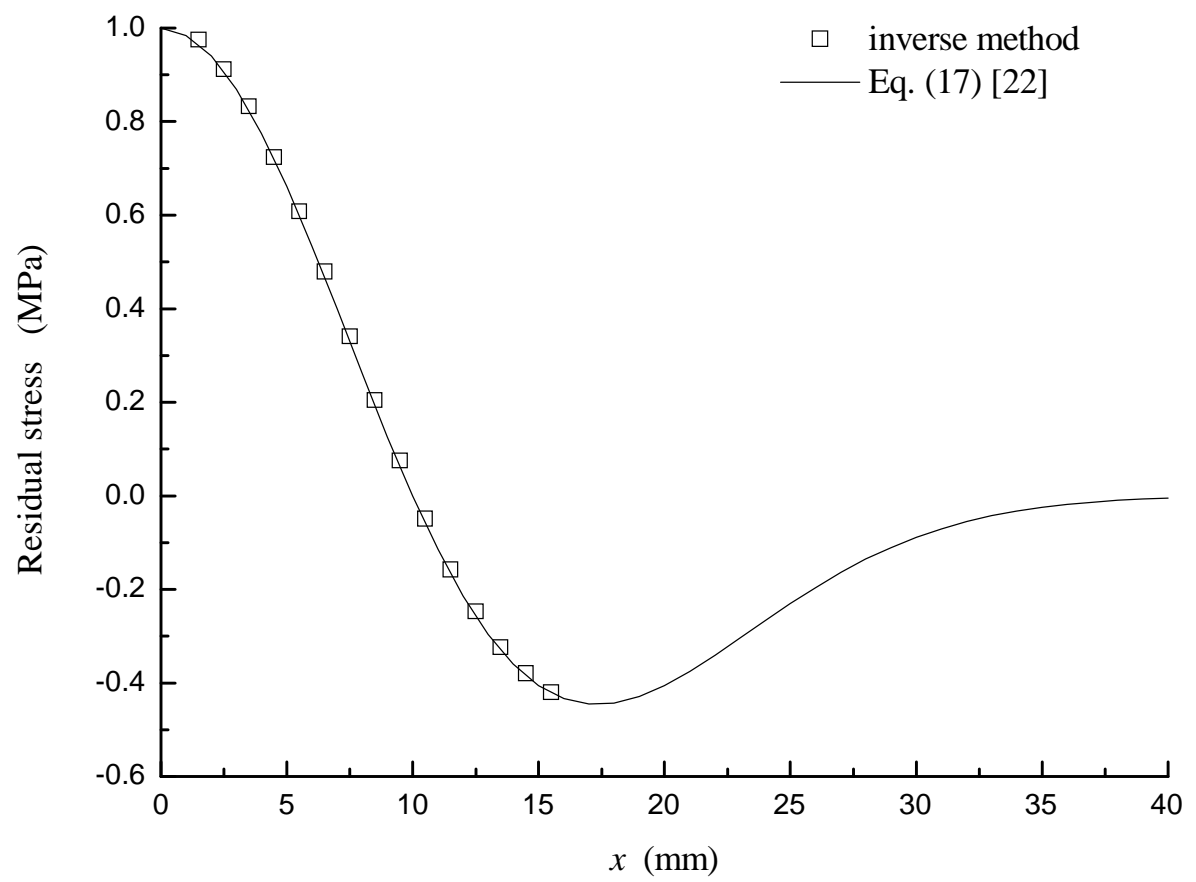

Fig. 9 Comparison of the residual stresses obtained by the inverse method and the given distribution by Eq. (17)

\section{Case study: evaluating residual stresses of VPPA welded 2024 joint}

Test sample in $[7,8]$ is used in this study that is an $\mathrm{M}(\mathrm{T})$ geometry, $W=80 \mathrm{~mm}$, made of aluminium alloy 2024-T351. The sample contains a longitudinal weld by single pass autogenous VPPA welding process. Base material properties are $E=73 \mathrm{GPa}$, yield and ultimate tensile strengths 372 and $470 \mathrm{MPa}$, respectively. Crack growth rate test results were reported in [7,8]. Material constants $C, n, p, q$ used in the NASGRO crack growth rate equation, i.e. eq. (3), are available in [20] and also listed here, $C=1.707 \mathrm{E}-10, n=3.353, p=$ $0.5, q=1$.

Measured $\mathrm{d} a / \mathrm{d} N$ vs. $a$ data from four test cases are used here, i.e. constant applied $\Delta K$ ( $\Delta K=4,6,11 \mathrm{MPa} \sqrt{\mathrm{m}}, R=0.1)$ and constant amplitude applied stress $(\Delta \sigma=42.6 \mathrm{MPa}$, $R=0.6$ ), which is taken from [7,8] and shown in Fig. 10. First, $K_{\text {res }}$ are obtained by solving eq. (9) by a numerical iterative method using the software MATHCAD, and the results for the four cases are shown in Fig. 11. Since, $K_{\text {res }}$ is actually a crack tip parameter derived from an existing and unique residual stress field, its value should not be affected by the loading conditions adopted in the FCG tests. Therefore, $K_{\text {res }}$ values obtained from the aforementioned four different loading condition tests are averaged to reduce the influence of the scatters in testing. Second, calculated average $K_{\text {res }}$ is substituted to eq. (15) to find the corresponding residual stress distribution $\mathbf{S}_{\text {res }}$. The calculated residual stress distribution and the measured [7-8] are shown in Fig. 12. The trend and magnitude of the residual stress distribution are modelled correctly, but there are differences in the magnitude with the measured data. The differences arise partially from the possible scatter in the $\mathrm{d} a / \mathrm{d} N$ vs. $a$ test data and partially from using the base material constants in eq. (9) (rather than weld metal constants) to describe crack growth in welds, which will be discussed in section 5.2. A scatter band of about $20 \mathrm{MPa}$ in the measure residual stress data [23] could also contribute to the discrepancy. 
It should be pointed out that the $\mathbf{B}$ matrix is associated with the geometrical configuration of a specimen, hence the $\mathbf{B}$ matrix used in this example, which is listed in Appendix 2, is different slightly from the one presented in Section 3.3 (Appendix 1) due to the finite width of this specimen. The relationship between $B_{i j}$ and panel width $W$ will be mentioned in section 5.1.

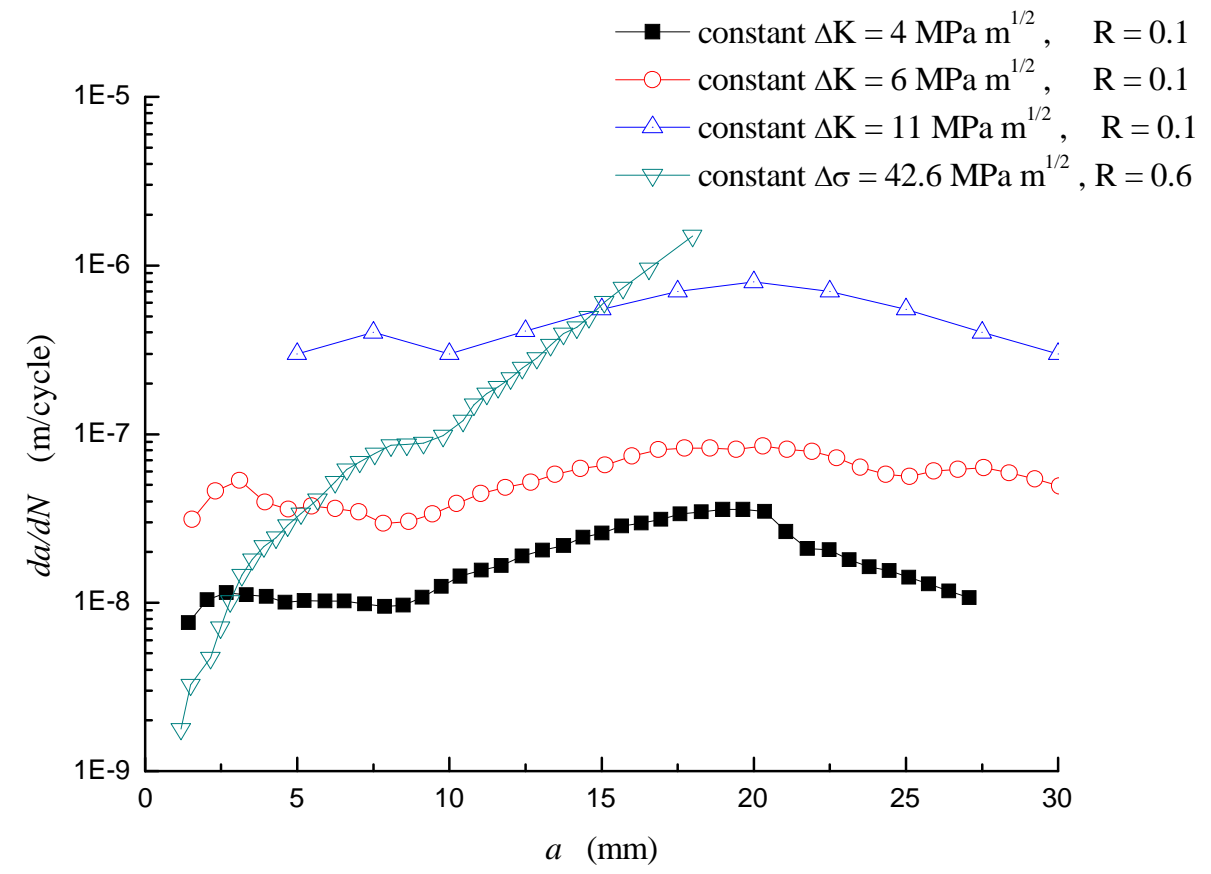

Fig. $10 d a / d N$ test data $[7,8]$

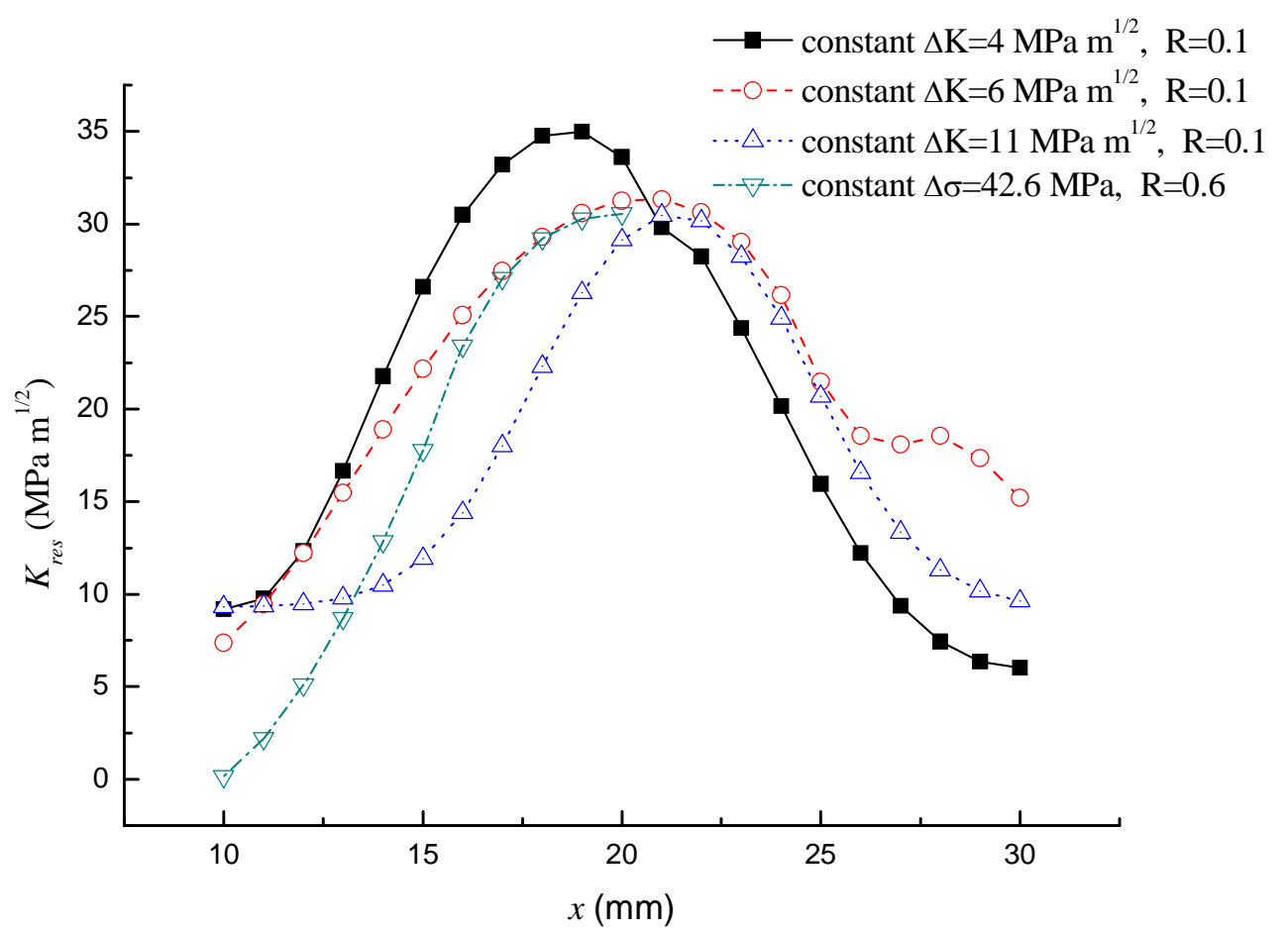

Fig. 11 Calculated $K_{\text {res }}$ by solving eq. (9). 


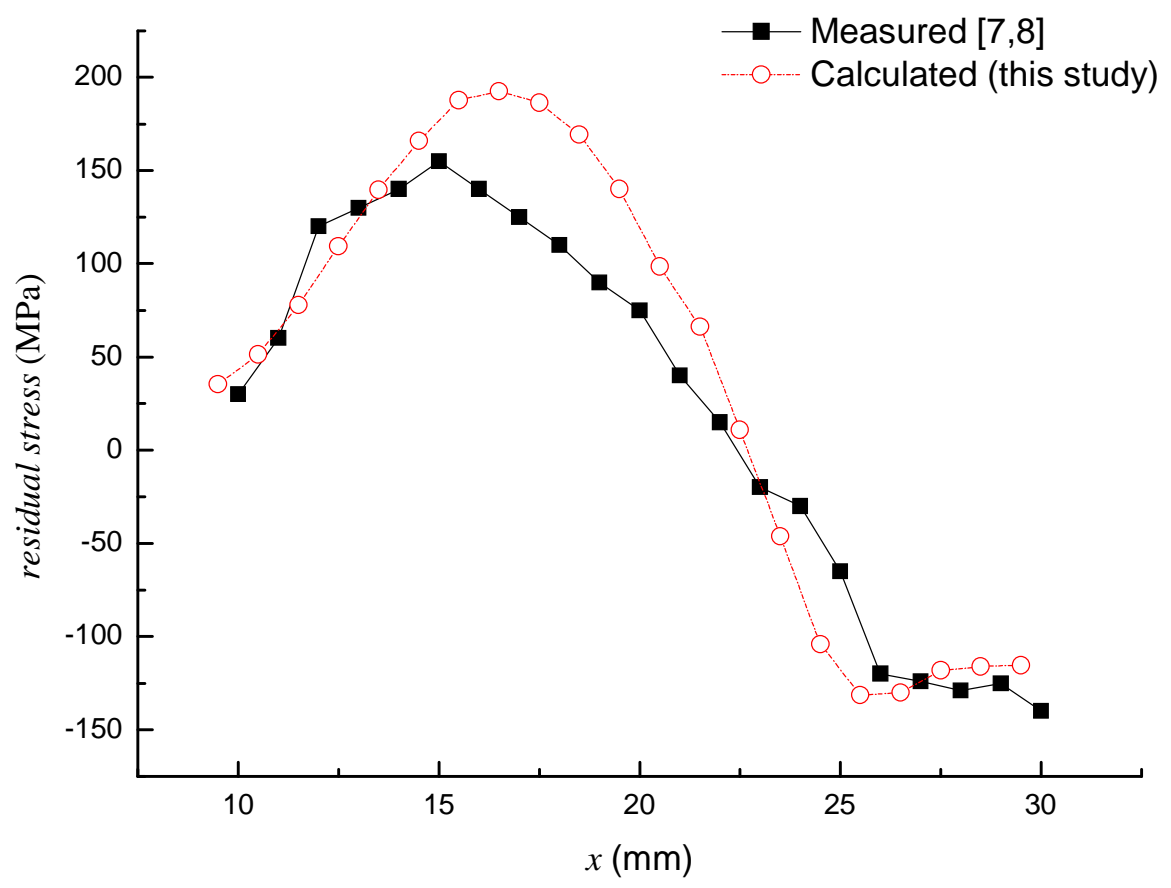

Fig. 12 Calculated average residual stress by the inverse method and comparison with the test measured.

\section{Discussion}

\subsection{About the B matrix}

It has been previously mentioned that the elements in the $\mathbf{B}$ matrix are essentially the SIF values corresponding to a crack length under a unit stress applied at a specified location. The SIF at crack length $a_{i}$ due to an arbitrary set of residual stresses $\mathbf{S}_{\text {res }}$ can be obtained by a summation of the product of these stresses and $B_{i j}$, eq. (19). Since $\mathbf{B}$ is a lower triangular matrix, i.e. $B_{i j}=0$ when $j>i$, the summation only needs to be made for $j=1-i$ ( $i$ being the crack tip location index).

$$
K_{\text {res }}\left(a_{i}\right)=\sum_{j=1}^{i} B_{i j} \cdot S_{\text {res } j}
$$

Although $B_{i j}$ and $S_{\text {res } j}$ are discrete values corresponding to $a_{i}$ and $x_{j}$, it could be argued that $B_{i j}$ and $S_{r e s j}$ can also be described by continuous functions expressed by eqs. (20) and (21).

$$
\begin{gathered}
B=g(a, x), \quad B_{i j}=g\left(a_{i}, x_{j}\right) \\
S_{\text {res }}=\sigma(x), \quad S_{\text {res } j}=\sigma\left(x_{j}\right)
\end{gathered}
$$

Then, eq. (19) can be rewritten as:

$$
K_{r e s}=\int_{0}^{a} \sigma(x) g(a, x) \mathrm{d} x
$$

Eq. (22) is consistent with the weight function in form [24]. It has been pointed out in [25] that $g(a, x)$ is numerically equal to the $K$ due to a couple of unit forces applied in the $x$ position for a crack of length $a$, which suggested a way to obtain weight functions numerically with a series of FE calculations. Therefore, for simple geometries for which weight function are available, the $\mathbf{B}$ matrix can also be calculated by WFM. 
A comparison of the B matrixes for a $\mathrm{M}(\mathrm{T})$ geometry determined by WFM and FEM are given below. Wu and Carlsson's weight function [26] is used here that is for a centre crack in a finite width plate subjected to two linearly distributed stress segments symmetrically acting on the crack faces in the interval $\left|x_{1}^{\prime}\right| \leq\left|x^{\prime}\right| \leq\left|x_{2}^{\prime}\right|$. The SIF for this configuration [26] can be expressed by eq. (23) and (24).

$$
\begin{gathered}
\sigma\left(x^{\prime}\right) / \sigma_{0}=k\left|x^{\prime}\right|+b, \quad\left|x_{1}^{\prime}\right| \leq\left|x^{\prime}\right| \leq\left|x_{2}^{\prime}\right| \\
K=f \sigma_{0} \sqrt{\pi a^{\prime} W}, \quad f=k f_{l}+b f_{c}
\end{gathered}
$$

where, $\sigma_{0}$ is a nominal stress, $a^{\prime}$ and $x^{\prime}$ are non-dimensional crack length and coordinate, respectively, defined by $a^{\prime}=2 a / W, x^{\prime}=2 x / W$, and:

$$
\begin{aligned}
& f_{l}=\frac{a^{\prime}}{\pi}\left[\sum_{i=1}^{3} \frac{\beta_{i}\left(a^{\prime}\right)}{2 i-1}\left[1-\left(\frac{x^{\prime}}{a^{\prime}}\right)^{2}\right]^{i-\frac{1}{2}}\right]_{x_{2}^{\prime}}^{x_{1}^{\prime}}, \quad f_{c}=\frac{1}{\pi}\left[\sum_{i=1}^{3} \beta_{i}\left(a^{\prime}\right) Q_{i}\left(\frac{x^{\prime}}{a^{\prime}}\right)\right]_{x_{1}^{\prime}}^{x_{2}^{\prime}} \\
& Q_{1}\left(x^{\prime} / a^{\prime}\right)=\sin ^{-1}\left(x^{\prime} / a^{\prime}\right), \quad i=1 \\
& Q_{i}\left(x^{\prime} / a^{\prime}\right)=\frac{1}{2 i-1}\left\{\frac{x^{\prime}}{a^{\prime}}\left[1-\left(\frac{x^{\prime}}{a^{\prime}}\right)^{2}\right]^{i-\frac{3}{2}}+(2 i-3) Q_{i-1}\left(x^{\prime} / a^{\prime}\right)\right\}, \quad i \geq 2 \\
& \beta_{1}\left(a^{\prime}\right)=2, \beta_{2}\left(a^{\prime}\right)=\frac{\pi a^{\prime}}{2} \tan \left(\frac{\pi a^{\prime}}{2}\right), \beta_{3}\left(a^{\prime}\right)=0 \text { for } H / W \geq 2.0
\end{aligned}
$$

For the $\mathrm{M}(\mathrm{T})$ sample under unit stress, let $k=0, b=1,\left(x_{j}^{\prime}-x_{j-1}^{\prime}\right) \cdot W=1$, then $B_{i j}$ can be calculated by eq. (24) and the result is expressed as:

$$
B_{i j}=\frac{K}{\sigma_{0}}=\sqrt{\frac{a_{i}^{\prime} W}{\pi}}\left[\sum_{i=1}^{3} \beta_{i}\left(a_{i}^{\prime}\right) Q_{i}\left(\frac{x^{\prime}}{a_{i}^{\prime}}\right)\right]_{x_{j-1}^{\prime}}^{x_{j}^{\prime}}
$$

This function also shows the relationship of $B_{i j}$ with the width of the $\mathrm{M}(\mathrm{T})$ specimen investigated.

The WFM determined $B_{i j}$ values are plotted in Fig. 13 against the FE results for the M(T) specimen used in Section 4. The agreement is exact; hence the proposed FE method to find the $\mathbf{B}$ matrix is validated by a well-established weigh function method; the FE based inverse method can be used for complex geometries where corresponding weight functions may not be available. 


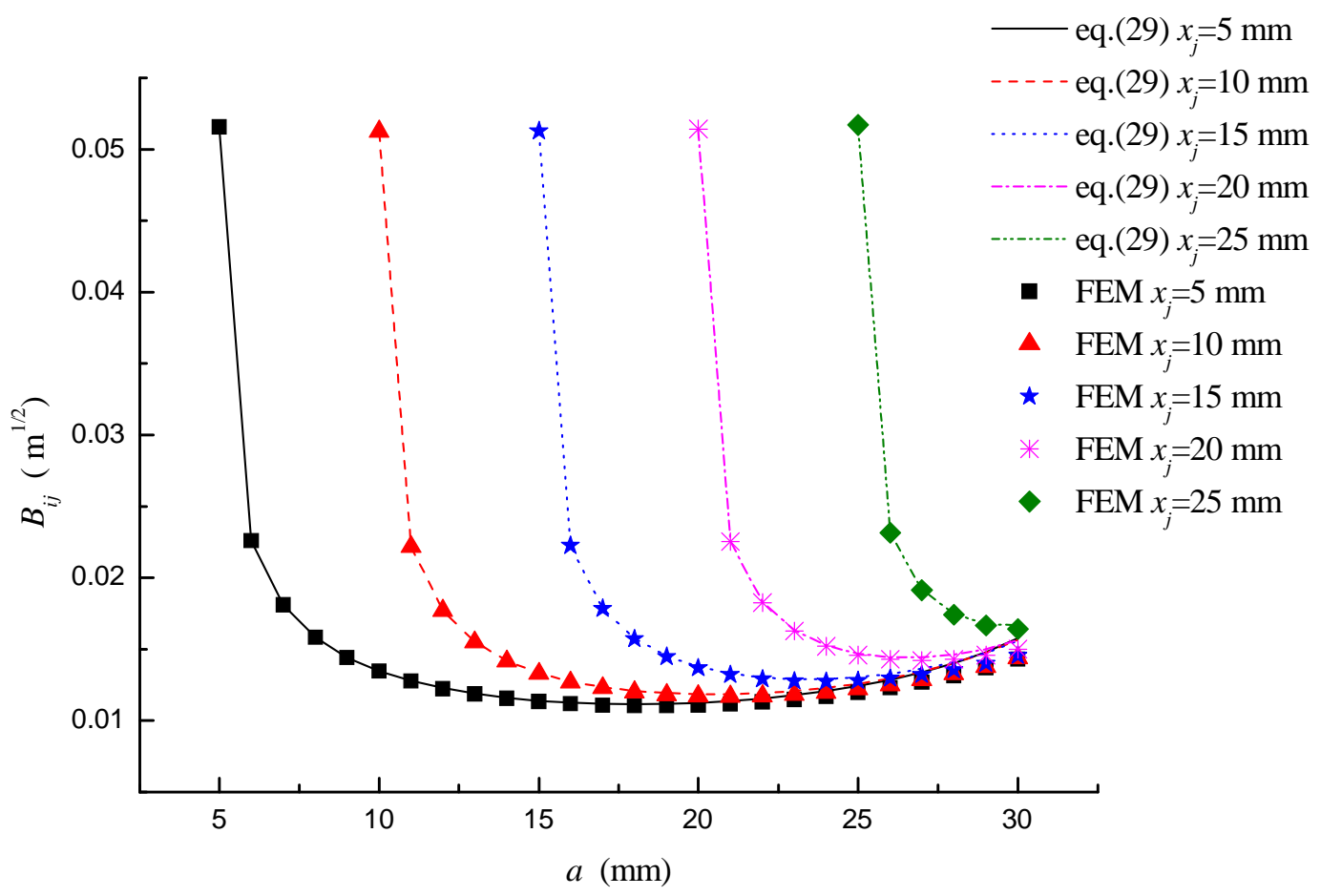

Fig. 13 Comparison of $B_{i j}$ values determined by FEM and WFM ( $\left.W=80 \mathrm{~mm}\right)$.

\subsection{Limitation and applicability of the inverse method}

The discrepancy between the calculated and measured residual stresses shown in Fig. 12 arise partially from the scatters in the $\mathrm{d} a / \mathrm{d} N$ test data and partially from using eq. (9) to describe fatigue crack growth rates in the weld metal. For the latter, following observations are made. In the NASGRO equation, material constants $C, n, p$ and $q$ are obtained from testing samples made of the base material. For welded test samples, changes in the weld microstructures and hardness could affect the crack growth rates; hence the values of these material constants. This comment also applies to the use of any other empirical crack growth laws. Crack growth rates have been found to be noticeably slower in softer zones (reduce hardness) within the HAZ under constant $\Delta K$ loads [7-8]. Pouget and Reynolds have investigated fatigue crack growth in FSW AA2050 C(T) specimens with the crack propagating perpendicular to the weld under constant $\Delta K$ [27]. They have found that residual stresses have a major effect on the FCG rates, although changes in the microstructure and hardness also influence FCG rates, and that using the nugget $\mathrm{d} a / \mathrm{d} N$ data gives better prediction than using the base material data. For better understanding this points, considering that $(d a / d N)_{w}$ and $(d a / d N)_{b}$ are the crack growth rates of the weld metal and base material, respectively, then:

$$
(d a / d N)_{w}=(d a / d N)_{b}+\Delta_{1}+\Delta_{2}
$$

where $\Delta_{1}$ and $\Delta_{2}$ are the changes in crack growth rate due to residual stresses and microstructure change, respectively. It is obvious that $(d a / d N)_{w} \neq(d a / d N)_{b}+\Delta_{1}$, if $\Delta_{2} \neq 0$. When calculating $K_{r e s}$ using Eq. (9), it is assumed that

$$
\left(\frac{\mathrm{d} a}{\mathrm{~d} N}\right)_{w}=\left(\frac{\mathrm{d} a}{\mathrm{~d} N}\right)_{b}+\Delta_{1}=C\left[\left(\frac{1-f_{\text {eff }}}{1-R_{\text {eff }}}\right) \Delta K_{a p p}\right]^{n} \frac{\left(1-\frac{\Delta K_{\text {th eff }}}{\Delta K_{\text {app }}}\right)^{p}}{\left(1-\frac{K_{\text {app max }}+K_{\text {res }}}{K_{\text {crit }}}\right)^{q}}
$$


It can be deduced that if $(d a / d N)_{w}>(d a / d N)_{b}+\Delta_{1}$, then $K_{\text {res }}$ will be overestimated, otherwise, if $(d a / d N)_{w}<(d a / d N)_{b}+\Delta_{1}, K_{\text {res }}$ will be underestimated. Assume the error in $K_{\text {res }}$ is $\alpha$, then the resultant error in $S_{\text {res }}$ is of the same order as that in $K_{\text {res }}$ according to Eq. (15) and Eq. (32).

$$
\mathbf{B}^{-1}\left(\alpha \mathbf{K}_{r e s}\right)=\alpha \mathbf{B}^{-1} \mathbf{K}_{r e s}=\alpha \mathbf{S}_{\text {res }}
$$

These also explain why the estimated residual stress in Fig. 12 is lower than the measured value in HAZ.

An example is given in Fig. 14 to illustrate the error in $K_{\text {res }}$ and $S_{\text {res }}$ obtained from the difference between $(d a / d N)_{w}$ and $(d a / d N)_{b}+\Delta_{1}$. In this example, considering $\Delta K_{a p p}=4 \mathrm{MPa} \sqrt{\mathrm{m}}, R=0.1,(d a / d N)_{w}$ is assumed to be $\left[(d a / d N)_{b}+\Delta_{1}\right] \times 110 \%$, then the error of $K_{\text {res }}$ and $S_{\text {res }}$ is within $10 \%$ to $20 \%$.

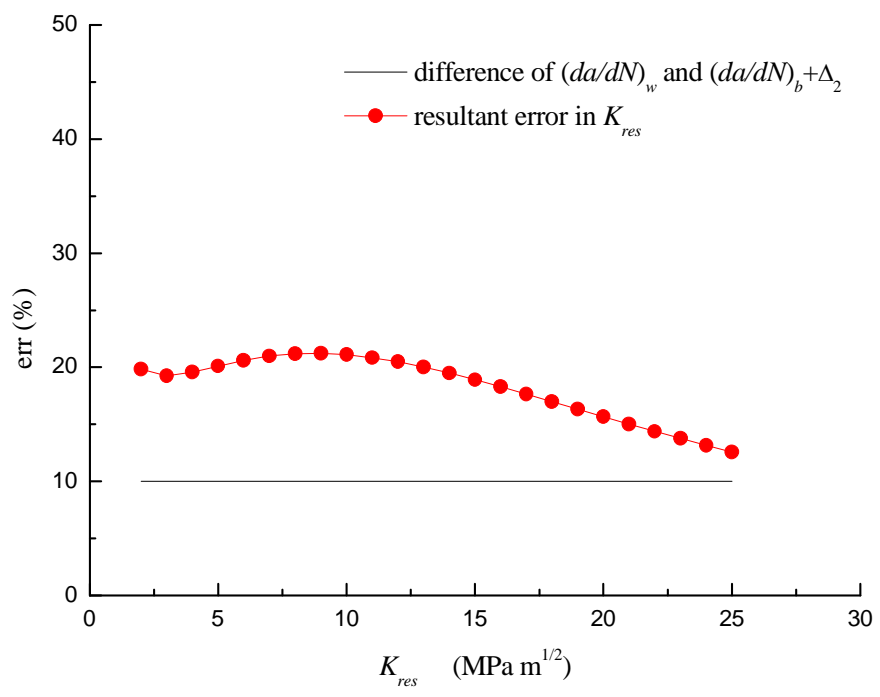

Fig. 14 Error in $K_{\text {res }}$ resulting from the crack growth estimation model

A way to solve this problem is to measure fatigue crack growth rates using welded samples with residual stresses being totally released. Therefore measured material constants in FCG laws reflect weld microstructure properties. Effect of residual stresses can then be considered in the calculation of stress intensity factors.

This problem, i.e. change in material properties in weld zone, also exists in other mechanical methods including the cut compliance and the on-line crack-compliance method that are used to determine the $K_{\text {res }}$, because the compliance relationships between measured strain/displacement and stress are based on the base material.

However, for the $\mathrm{M}(\mathrm{T})$ specimen used in this study, an initial crack was made at the weld centre. When the crack propagated from the weld to base material, micro-structural effect should have less influence on crack growth rates compared to the $\mathrm{C}(\mathrm{T})$ sample in [27] where crack propagated from the base material region towards the weld. Therefore, the method can provide reasonably good prediction of the residual stress.

\subsection{Crack closure effect}

The modified NASGRO equation, eq. (9), has been employed in this work that takes into account of plasticity-induced crack closure by the parameter $f$, which is expressed eq. (7). 
Since $f$ is a function of the effective stress ratio $R_{\text {eff }}$ (eq. 3), the contribution of weld residual stresses to crack closure is considered through the calculation of residual stress intensity factors.

\section{Conclusions}

An inverse method is presented for evaluating thermal residual stresses in welded structures via measured fatigue crack growth rates. The method is based on the fracture mechanics crack growth law and superposition law for extracting the residual stress intensity factor from measured crack growth rate data and on the establishment of a set of linear algebraic equations representing the relationship between the residual stresses and residual stress intensity factors.

The method is firstly validated by an assumed analytically residual stress distribution and well established corresponding stress intensity factor, for which the agreement is exact. The method is then applied to an $\mathrm{M}(\mathrm{T})$ sample made of 2024-T3 alloy with a longitudinal weld and tested under constant amplitude load and constant stress intensity factor ranges. Agreement with measured residual stresses is reasonably good. Causes for small discrepancy from the measured data are identified and discussed.

In terms of numerical modeling techniques, inputting initial residual stresses into an FE model and calculation of the unit stress SIF (the $\mathbf{B}$ matrix) are presented in detail. The FE evaluated B matrix for the $\mathrm{M}(\mathrm{T})$ geometry is validated by a weight function solution. Therefore, the proposed numerical procedure for determining weld residual stresses can be employed for complex geometries, for which FEM is more versatile and robust.

The proposed inverse method can be employed for cases where crack growth path is perpendicular to the welds and the influence of longitudinal residual stresses is more significant than changes in the weld microstructure.

\section{References}

1. Glinka G. Effect of residual stresses on fatigue crack growth in steel weldments under constant and variable amplitude load. In: Frac. Mech., ASTM STP 677, 1979: 198-214.

2. Terada, H. Analysis of the stress intensity factor of a crack perpendicular to the welding bead. Eng Frac Mech, 8 (1976): 441-444.

3. Bussu G, Irving PE. The role of residual stress and heat affected zone properties on fatigue crack propagation in friction stir welded 2024-T351 aluminium joints, Int J Fatigue, 25(2003): 77-88.

4. Ghidini T, Dalle Donne C. Fatigue crack propagation assessment based on residual stresses obtained through cut-compliance technique, Fatigue \& Fracture of Engineering Materials and Structures, 30(2006): 214-222.

5. Fratini L, Pasta S, Reynolds AP, Fatigue crack growth in 2024-T351 friction stir welded joints: Longitudinal residual stress and microstructural effects, Int J Fatigue, 31(2009): 495-500.

6. Edwards L, Fitzpatrick ME, Irving PE, Sinclair I, Zhang X, Yapp D. An integrated approach to the determination and consequences of residual stress on the fatigue performance of welded aircraft structures. ASTM International, Vol. 3, Feb 2006. Online ISSN: 1546-962X. Paper ID JAI12547; available online at www.astm.org.

7. Brouard J, Lin J, Irving PE. Effects of residual stress and fatigue crack closure during fatigue crack growth in welded 2024 aluminium. In : Proc. of Fatigue 2006, June 2006, Atlanta, USA.

8. Servetti $G$, Zhang $X$. Predicting fatigue crack growth rate in a welded butt joint: the role of effective $R$ ratio in accounting for residual stress effect. Eng Frac Mech 76 (2009): 1589-1602. 
9. Itoh YZ, Suruga S, Kashiwaya H. Prediction of fatigue crack growth rate in welding residual stress field. Eng Frac Mech, 33 (1989): 397-407.

10. Beghini M, Bertini L, Vitale E. Fatigue crack growth in residual stress fields: experimental results and modelling, Fatigue \& Fracture of Engng Material \& Structures, 17(1994): 1433-1444.

11. R Bao, X Zhang, W Ahmed Yahaya. Evaluating stress intensity factors due to weld residual stresses by the weight function and finite element methods, Eng Fract Mech, 2010; 77: 25502566.

12. Fitzpatrick ME, Fry AT, Holdway P, Kandil FA, Shackleton J, Suominen L, Determination of residual stresses by X-ray diffraction, National Physical Laboratory Good Practice Guide No. 52, 2005.

13. Gunguly S, Fitzpatrick ME, Edwards L, Use of neutron and synchrotron X-ray diffraction for evaluation of residual stresses in a 2024-T351 aluminium alloys variable-polarity plasma-arc weld. Metall Mater Trans A 2006; 37: 411-20.

14. ASTM E837-08: Standard Test Method for Determining Residual Stresses by the Hole-Drilling Strain-Gauge Method.

15. Prime MB. Residual stress measurement by successive extension of a slot: the crack compliance method. Appl Mech Rev 52 (1999): 75-96.

16. Donald, J.K., Lados, D.A. An integrated methodology for separating closure and residual stress effects from fatigue crack growth rate data, Fatigue and Fracture of Engineering Materials and Structures, 30 (2007): 223-230.

17. Pasta, S., Reynolds, A.P. Evaluation of residual stresses during fatigue test in an FSW joint, Strain, 44 (2008): 147-152.

18. Schindler HJ. Determination of residual stress distributions from measured stress intensity factors. Int J Fracture 1995; 74: R23-R30.

19. Anderson T L. Fracture Mechanics, Fundamentals and Applications. 3rd ed. Norway: CRC Press, Taylor and Francis Group; 2005.

20. Harter JA. AFGROW users guide and technical manual, AFRL-VA-WP-TR-2006-xxxx, AFGROW, version 4.0011.14, June 2006. Website (accessed April 2009): http://www.siresearch.info/projects/afgrow/downloads/afgrow/download.php.

21. Press WH, Teukolsky SA, Vetterling BP, Flannery WT. Numerical Recipes in C - The Art of Scientific Computing, $2^{\text {nd }}$ Ed. Cambridge University Press, Cambridge, 1992 (Ch 9 for solving eq. 3; Ch 2 for eq. 9).

22. Tada H, Paris PC, Irwin GR. The stress analysis of cracks handbook (Third edition).New York, NY, USA: The American Society of Mechanical Engineers; 2000.

23. Liljedahl CDM, Brouard J, Zanellato O, Lin J, Tan ML, etc. Weld residual stress effects on fatigue crack growth behaviour of aluminium alloy 2024-T351, Int J Fatigue, 31(2009): 1081-1088.

24. Bueckner H F. A novel principle for computation of stress intensity factors. Z. Angew. Math. Mech., 1970, pp. 529-546.

25. Beghini M, Bertini L. Fatigue crack propagation through residual stress fields with closure phenomena. Eng Frac Mech, 36 (1990): 379-387.

26. Wu X R, Carlsson A J. Weight Functions and Stress Intensity Factor Solutions. Pergamon Press, Oxford, 1991 (Ch 2).

27. Pouget G, Reynolds AP. Residual stress and microstructure effects on fatigue crack growth in AA2025 friction stir welds, Int J Fatigue, 30(2008): 463-472. 


\section{APPENDIX}

1. B matrix for the $\mathrm{M}(\mathrm{T})$ geometry of whole width $W=600 \mathrm{~mm}$ used in section 3.3 (unit: $\mathrm{MPa} \sqrt{\mathrm{m}}$ )

\begin{tabular}{|c|c|c|c|c|c|c|c|c|c|c|c|c|c|c|c|c|}
\hline $\begin{array}{r}\begin{array}{r}x_{j-1} \sim x_{j} \\
(\mathrm{~mm})\end{array} \\
a_{i} \\
(\mathrm{~mm})\end{array}$ & $0 \sim 2$ & $2 \sim 3$ & $3 \sim 4$ & $4 \sim 5$ & $5 \sim 6$ & $6 \sim 7$ & $6 \sim 8$ & $6 \sim 9$ & $9 \sim 10$ & $10 \sim 11$ & $11 \sim 12$ & $12 \sim 13$ & $13 \sim 14$ & $14 \sim 15$ & $\ldots$ & $29 \sim 30$ \\
\hline 2 & 0.0792 & & & & & & & & & & & & & & & \\
\hline 3 & 0.0450 & 0.052 & & & & & & & & & & & & & & \\
\hline 4 & 0.0372 & 0.023 & 0.0515 & & & & & & & & & & & & & \\
\hline 5 & 0.0327 & 0.0184 & 0.0225 & 0.0513 & & & & & & & & & & & & \\
\hline 6 & 0.0296 & 0.0159 & 0.0179 & 0.0222 & 0.0511 & & & & & & & & & & & \\
\hline 7 & 0.0272 & 0.0143 & 0.0155 & 0.0175 & 0.0219 & 0.051 & & & & & & & & & & \\
\hline 8 & 0.0253 & 0.0132 & 0.0139 & 0.0151 & 0.0173 & 0.0217 & 0.0509 & & & & & & & & & \\
\hline 9 & 0.0239 & 0.0123 & 0.0128 & 0.0136 & 0.0149 & 0.0171 & 0.0216 & 0.0508 & & & & & & & & \\
\hline 10 & 0.0226 & 0.0116 & 0.0119 & 0.0125 & 0.0134 & 0.0147 & 0.0169 & 0.0215 & 0.0507 & & & & & & & \\
\hline 11 & 0.0216 & 0.011 & 0.0112 & 0.0117 & 0.0123 & 0.0132 & 0.0145 & 0.0168 & 0.0214 & 0.0506 & & & & & & \\
\hline 12 & 0.0206 & 0.0105 & 0.0107 & 0.011 & 0.0115 & 0.0121 & 0.013 & 0.0144 & 0.0167 & 0.0213 & 0.0506 & & & & & \\
\hline 13 & 0.0198 & 0.01 & 0.0102 & 0.0104 & 0.0108 & 0.0113 & 0.0119 & 0.0129 & 0.0143 & 0.0166 & 0.0212 & 0.0505 & & & & \\
\hline 14 & 0.0192 & 0.0096 & 0.0098 & 0.01 & 0.0103 & 0.0106 & 0.0111 & 0.0118 & 0.0128 & 0.0142 & 0.0165 & 0.0211 & 0.0505 & & & \\
\hline 15 & 0.0184 & 0.0093 & 0.0094 & 0.0096 & 0.0098 & 0.0101 & 0.0105 & 0.011 & 0.0117 & 0.0127 & 0.0141 & 0.0164 & 0.0211 & 0.0504 & & \\
\hline$\ldots$ & $\ldots$ & $\ldots$ & $\ldots$ & $\ldots$ & $\ldots$ & $\ldots$ & $\ldots$ & $\ldots$ & $\ldots$ & $\ldots$ & $\ldots$ & $\ldots$ & $\ldots$ & $\ldots$ & $\ldots$ & \\
\hline 30 & 0.0134 & 0.0067 & 0.0068 & 0.0068 & 0.0068 & 0.0068 & 0.0069 & 0.0069 & 0.0070 & 0.0071 & 0.0071 & 0.0072 & 0.0074 & 0.0075 & $\cdots$ & 0.0503 \\
\hline
\end{tabular}


2. B matrix for the $\mathrm{M}(\mathrm{T})$ geometry of whole width $W=80 \mathrm{~mm}$ used in section 4 (unit: $\mathrm{MPa} \sqrt{\mathrm{m}}$ )

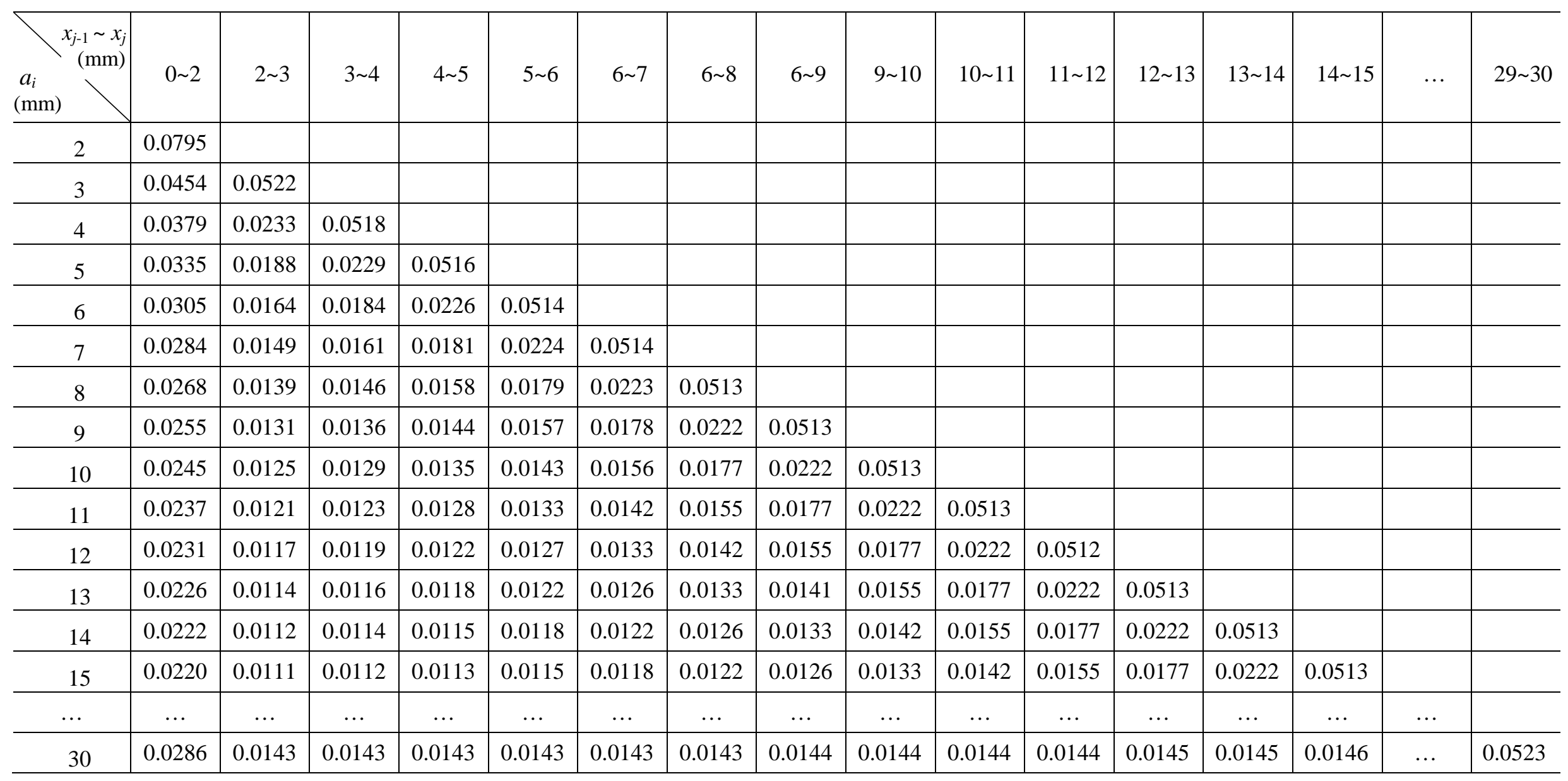

